\title{
Effects of rumen cannulation on dissolved gases and methanogen community in dairy cows
}

\author{
Rong Wang, ${ }^{1,2}$ Min Wang, ${ }^{2,3 *}$ Xiu Min Zhang, ${ }^{2}$ Jiang Nan Wen, ${ }^{1,2}$ Zhi Yuan Ma, ${ }^{2}$ Dong Lei Long, ${ }^{1,2}$ \\ Jin Ping Deng, ${ }^{1,4 *}$ and Zhi Liang Tan ${ }^{2,3}$ \\ ${ }^{1}$ College of Animal Science and Technology, Hunan Agricultural University, Changsha 410128, P. R. China \\ ${ }^{2}$ Key Laboratory for Agro-Ecological Processes in Subtropical Region, National Engineering Laboratory for Pollution Control and Waste Utilization \\ in Livestock and Poultry Production, Institute of Subtropical Agriculture, The Chinese Academy of Sciences, Changsha, Hunan 410125, \\ P. R. China \\ ${ }^{3}$ Hunan Co-Innovation Center of Animal Production Safety, Changsha, Hunan 410128, P. R. China \\ ${ }^{4}$ Guangdong Provincial Key Laboratory of Animal Nutrition Control, Subtropical Institute of Animal Nutrition and Feed, College of Animal Science, \\ South China Agricultural University, Guangzhou, Guangzhou 510642, P. R. China
}

\section{ABSTRACT}

Rumen cannulation is a widely employed technique in ruminant nutrition research. However, the gap between skin and rumen cannula can cause leakage of fermentation gases and influx of atmospheric air, which may adversely affect the anaerobic environment in the rumen. The present study was designed to investigate the effects of rumen cannulation on headspace gases, dissolved gases, fermentation end products, and methanogen community in the rumen of dairy cows. Eight Holstein cows were used in the experiment. Four cows were surgically fitted with rumen cannulas, whereas the other 4 intact cows were used as control. Rumen cannulation decreased gaseous hydrogen and methane concentrations, dissolved carbon dioxide concentration, and relative abundances of Methanosphaera, and increased the saturation factor of dissolved hydrogen and dissolved methane, dissolved methane concentration, volatile fatty acid concentration, $16 \mathrm{~S}$ ribosomal RNA gene copies of methanogens, and Simpson index of methanogen community. In summary, rumen cannulation causes a reduction in headspace gaseous hydrogen and gaseous methane, which may not decrease dissolved gas concentrations due to an increase in saturation factors. Furthermore, rumen cannulation alters methanogen community with increased methanogen population and decreased relative abundances of Methanosphaera. Key words: dissolved methane, dissolved hydrogen, methanogenesis, rumen fermentation

Received June 10, 2018.

Accepted November 28, 2018.

*Corresponding authors: mwang@isa.ac.cn and dengjinping@aliyun .com

\section{INTRODUCTION}

Surgical rumen cannulation is the most frequently employed technique to facilitate access to the reticulorumen and thus is widely used in ruminant nutrition research (Mendoza et al., 2016; Mutsvangwa et al., 2016). The wide application of rumen cannulation is based on the assumption that it does not have adverse effects on rumen digestive, physiological, and metabolic functions. However, the laparotomy incision is frequently larger than the diameter of the cannula, and the muscle and skin support around the cannula can be compromised, leading to leakage of fermentation gases and rumen content (Grovum, 1989; McSweeney, 1989; Rafee et al., 2015). Leakage of fermentation gases from the rumen can be associated with increases in concentrations of gaseous nitrogen $\left(\mathrm{gN}_{2}\right)$ and oxygen $\left(\mathrm{gO}_{2}\right)$, and reductions in carbon dioxide $\left(\mathbf{g C O}_{2}\right)$, methane $\left(\mathbf{g C H}_{4}\right)$, and hydrogen $\left(\mathbf{g H}_{2}\right)$ concentrations in the headspace of the rumen. Increased headspace $\mathrm{gO}_{2}$ is likely to alter the anaerobic microbial ecosystem and physiological function of the rumen (Wang et al., 2018a), leading to changes in rumen methanogenesis (Moate et al., 2013).

According to the theory of thermodynamic equilibrium, headspace gas pressure determines the concentrations of dissolved gases in the liquid phase of rumen (Wiesenburg and Guinasso, 1979). However, dissolved gases, such as dissolved $\mathrm{CH}_{4}\left(\mathbf{d C H}_{4}\right), \mathrm{H}_{2}\left(\mathbf{d H}_{\mathbf{2}}\right)$, and $\mathrm{CO}_{2}\left(\mathbf{d C O}_{2}\right)$, are always supersaturated in the liquid phase of rumen (Wang et al., 2016a). Therefore, it is uncertain if reduced concentrations of $\mathrm{gCO}_{2}, \mathrm{gCH}_{4}$, and $\mathrm{gH}_{2}$ alter the concentrations of the corresponding dissolved gases in the liquid phase of rumen. Rumen cannulation alters amplitude of contraction of the rumen (Hirayama and Katoh, 2005), which may affect rumen motility and thus further alter saturation factor of dissolved gases. Therefore, the objective of this study 
was to investigate the effects of rumen cannulation on ruminal dissolved gases and methanogenesis.

\section{MATERIALS AND METHODS}

All experimental procedures followed our institutional guidelines for the care and use of animals and were approved by the Animal Care Committee (approval number ISA-W-201703), Institute of Subtropical Agriculture, the Chinese Academy of Sciences, Changsha, China.

\section{Animals, Diet, and Experimental Design}

Eight Chinese Holstein dairy cows (mean \pm SD; parity, $2.86 \pm 0.78 ; \mathrm{BW}=508 \pm 20.2 \mathrm{~kg})$, including 4 lactating (DIM, $250 \pm 15 \mathrm{~d}$; milk yield, $13.8 \pm 0.98$ $\mathrm{kg} / \mathrm{d}$ ) and 4 nonlactating cows, were blocked in 4 pairs and allocated to 1 of 2 treatments according to lactating status, milk production, and BW. Four cows were surgically fitted with rumen cannula, whereas the other 4 cows were left intact and used as control. The rumen cannulas were made of rigid polyvinyl chloride and polyamide (inner diameter: $101.3 \mathrm{~mm}$ ) and fabricated at the Chinese Agricultural University in Beijing. During the experiment, cows were housed in tiestalls and individually fed a TMR consisting of $50 \%$ corn silage, $16 \%$ corn grain, $18 \%$ soybean meal, $10 \%$ wheat bran, $4 \%$ soybean oil, $0.5 \%$ calcium carbonate, $0.5 \%$ salt, and $1 \%$ premix (DM basis). The premix was formulated to provide $1,000,000 \mathrm{IU}$ of vitamin A, 200,000 IU of vitamin D, 1,250 IU of vitamin E, 8,000 $\mathrm{mg}$ of $\mathrm{Zn}, 80 \mathrm{mg}$ of Se, $120 \mathrm{mg}$ of I, 2,000 $\mathrm{mg}$ of $\mathrm{Fe}, 40 \mathrm{mg}$ of $\mathrm{Co}, 2,500$ $\mathrm{mg}$ of $\mathrm{Mn}$, and $2,000 \mathrm{mg}$ of $\mathrm{Cu}$ (per $\mathrm{kg}$ of premix). The TMR was offered for ad libitum intake. The experimental period ( $42 \mathrm{~d}$ ) consisted of $40 \mathrm{~d}$ of adaptation, followed by 2 sampling days on which headspace gas and rumen contents were sampled. The cows were fed twice daily at 0600 and $1500 \mathrm{~h}$ and had free access to fresh water.

\section{Rumen Sampling}

Rumen gases and contents were collected $0,+2.5$, and $+6 \mathrm{~h}$ relative to the commencement of the morning feeding on d 41 and 42. Headspace gas was collected by rumenocentesis according Moate et al. (1997). After shearing and disinfection ( $75 \%$ ethanol) of the skin, the gas cap of the central rumen was punctured with a 150-mm long, 14-gauge needle. A 50-mL syringe was attached to the needle to collect $30 \mathrm{~mL}$ of headspace gas from the rumen. To prevent contamination with residual air in the syringe of needle, $50 \mathrm{~mL}$ of initially sampled gas was discarded. The collected headspace gas was then injected into $10-\mathrm{mL}$ evacuated glass vials with a plastic screw cap for subsequent measurements of $\mathrm{gH}_{2}$ and $\mathrm{gCH}_{4}$ concentrations.

Rumen contents were collected from all 8 cows by stomach tubing as described by Wang et al. (2016b). Briefly, samples of rumen content were collected by inserting an oral stomach tube (Anscitech Co. Ltd., Wuhan, China) to the depth of about $180 \mathrm{~cm}$, so that the probe head could reach the central rumen. To avoid saliva contamination, approximately $150 \mathrm{~mL}$ of initially sampled rumen content was discarded. About $300 \mathrm{~mL}$ of rumen content was collected for subsequent measurement. Two other subsamples $(35 \mathrm{~mL})$ were transferred into 50-mL plastic syringes for immediate extraction of dissolved gases. Another subsample $(30 \mathrm{~mL})$ was immediately frozen in liquid $\mathrm{N}_{2}$ and then stored at $-80^{\circ} \mathrm{C}$ for extraction of DNA and subsequent microbial analyses. Samples of $20 \mathrm{~mL}$ of rumen content were collected for immediate measurement of rumen $\mathrm{pH}$ using a portable $\mathrm{pH}$ meter (Starter 300, Ohaus Instruments Co. Ltd., Shanghai, China). Samples of $10 \mathrm{~mL}$ of rumen content was centrifuged at $12,000 \times g$ for $10 \mathrm{~min}$ at $4^{\circ} \mathrm{C}$. A 1.5 $\mathrm{mL}$ of supernatant was transferred into sampling tubes containing $0.15 \mathrm{~mL}$ of $25 \%$ (wt/vol) metaphosphoric acid and stored at $-20^{\circ} \mathrm{C}$ overnight for subsequent VFA measurement.

\section{Sample Analysis and Calculations}

For analysis of dissolved gases, the plastic syringe containing $35 \mathrm{~mL}$ of rumen content was connected with a $20-\mathrm{mL}$ syringe containing $10 \mathrm{~mL}$ of pure $\mathrm{gN}_{2}$ $(>99.99 \%)$ via polyurethane tubing. The $\mathrm{gN}_{2}$ in $20-$ $\mathrm{mL}$ syringe was injected into $50-\mathrm{mL}$ syringe, and gases dissolved in the liquid phase were extracted into the gas phase by shaking at 200 revolutions/s for $5 \mathrm{~min}$ in an orbital shaker (WSZ-100A, Shanghai Yiheng Scientific Instruments Co., Ltd., Shanghai, China) to attain equilibrium between the liquid and gas phases. After recording the volumes of gas using a 20-mL syringe, gas samples were injected into $4-\mathrm{mL}$ evacuated glass vials with a plastic screw cap. The $\mathrm{gH}_{2}$ and $\mathrm{gCH}_{4}$ concentrations were measured by GC (Agilent 7890A, Agilent Inc., Palo Alto, CA) as described by Wang et al. (2016a). Concentrations of $\mathrm{dH}_{2}$ and $\mathrm{dCH}_{4}$ in the original rumen content were calculated by according to Wang et al. (2014):

$$
C_{\text {dgas }}=\frac{C_{g g a s}\left(\alpha_{g a s}+V_{g} / V_{l}\right)}{22.4},
$$


$\alpha_{H_{2}}=\exp \left[-47.8948+65.0368\left(\frac{100}{T}\right)+20.1709 \ln \left(\frac{T}{100}\right)\right]$,

$\alpha_{C H_{4}}=\exp \left[-68.8862+101.4953\left(\frac{100}{T}\right)+28.7314 \ln \left(\frac{T}{100}\right)\right]$,

where $C_{\text {dgas }}$ is the dissolved target gas $\left(\mathrm{dH}_{2}, \mu M\right.$, or $\left.\mathrm{dCH}_{4}, \mathrm{~m} M\right)$ concentration in the sampled rumen content; $C_{\text {ggas }}$ is the target gaseous gas $\left(\mathrm{gH}_{2}, \mu \mathrm{L} / \mathrm{L}\right.$, or $\mathrm{gCH}_{4}$, $\mathrm{mL} / \mathrm{L}$ ) concentration measured in the gas phase of the 20 -mL syringe at equilibrium after extraction of dissolved gases; $V_{g}$ is the gas volume $(\mathrm{mL})$ at equilibrium after extraction of dissolved gases, assuming $1 \mathrm{~atm}$ in the gas phase of the $20-\mathrm{mL}$ syringe; $V_{l}$ is the volume of rumen content $(\mathrm{mL}) ; T$ is the temperature in $\mathrm{K}(273+$ temperature in ${ }^{\circ} \mathrm{C}$ ); and $\alpha_{\text {gas }}$ is the Bunsen absorption coefficient (L/L) for target gas $\left(\mathrm{H}_{2}\right.$ or $\mathrm{CH}_{4}$; Wiesenburg and Guinasso, 1979).

Dissolved $\mathrm{CO}_{2}$ concentration in the original rumen content was calculated by combining equations using equations by Wang et al. (2017):

$$
\begin{gathered}
C_{\mathrm{TdCO}_{2}}=1,000\left(C_{\mathrm{eTdCO}_{2}}+\frac{V_{g} C_{g C \mathrm{O}_{2}}}{22.4 V_{l}}\right), \\
C_{\text {eTdCO }_{2}}=\alpha_{\mathrm{CO}_{2}} C_{g C O_{2}} 10^{\left(\mathrm{pH}-p K_{C O_{2}}\right)}+\alpha_{\mathrm{CO}_{2}} C_{g C O_{2}}, \\
C_{g C O_{2}}=\left(V_{g}-V_{N}-V_{g} C_{g C H_{4}}\right) / V_{l}, \\
\alpha_{\mathrm{CO}_{2}}=100 /\left\{2 2 . 4 \operatorname { e x p } \left[-6.8346+1.2817\left(\frac{10^{4}}{T}\right)\right.\right. \\
\left.\left.-3.7668\left(\frac{10^{6}}{T^{2}}\right)+2.997\left(\frac{10^{8}}{T^{3}}\right)\right]\right\},
\end{gathered}
$$

where $C_{\mathrm{TdCO}_{2}}$ is the total $\mathrm{dCO}_{2}$ concentration in the original rumen fluid; $C_{e T d C O}$ is the total $\mathrm{dCO}_{2}$ concentration $(\mathrm{m} M)$ in the rumen content at equilibrium after extraction; $\mathrm{C}_{\mathrm{gCO}_{2}}$ is the $\mathrm{gCO}_{2}$ concentration $(\mathrm{L} / \mathrm{L})$ measured in the gas phase of the $20-\mathrm{mL}$ syringe at equilibrium after extraction of dissolved gases; $C_{g_{C H}}$ is the $\mathrm{gCH}_{4}$ concentration $(\mathrm{L} / \mathrm{L})$ measured in the gas phase of the 20-mL syringe at equilibrium after extraction of dissolved gases; $V_{q}$ is the gas volume $(\mathrm{mL})$ at equilibrium after extraction of dissolved gases; $V_{l}$ is the volume of liquid $(\mathrm{mL}) ; V_{N}$ is the injected $\mathrm{gN}_{2}$ volume $(10$ $\mathrm{mL}) ; p \mathrm{~K}_{\mathrm{CO}_{2}}$ is the dissociation constant of bicarbonate and set to be $6.11 ; \alpha_{\mathrm{CO}_{2}}$ is the Bunsen absorption coef- ficient $(\mathrm{mol} / \mathrm{L} \cdot \mathrm{atm})$ for $\mathrm{CO}_{2}$; and $T$ is the temperature in $\mathrm{K}\left(273+\right.$ temperature in $\left.{ }^{\circ} \mathrm{C}\right)$.

The saturation factor $\left(S F_{\text {gas }}\right)$ was defined as the ratio of measured concentration of dissolved gases to predicted concentration of dissolved gases based on the theory of thermodynamic equilibrium (Wang et al., 2014):

$$
\begin{gathered}
S F_{g a s}=\frac{C_{d g a s}}{C_{h d g a s}}, \\
C_{h d g a s}=\frac{C_{\text {hgas }}}{22.4} \alpha_{\text {gas }},
\end{gathered}
$$

where $C_{\text {dgas }}$ is the measured dissolved target gas $\left(\mathrm{dH}_{2}\right.$, $\mu M$, or $\left.\mathrm{dCH}_{4}, \mathrm{~m} M\right)$ concentration in the sampled rumen content; $C_{\text {hdgas }}$ is the predicted target gas concentration $\left(\mathrm{dH}_{2}, \mu M\right.$, or $\left.\mathrm{dCH}_{4}, \mathrm{~m} M\right)$ based on the target gas concentration in the gas phase of rumen; $C_{\text {hgas }}$ is measured target gas concentration $\left(\mathrm{gH}_{2}, \mu \mathrm{L} / \mathrm{L}\right.$, or $\left.\mathrm{gCH}_{4}, \mu \mathrm{L} / \mathrm{L}\right)$ in the gas phase of rumen; $\alpha_{\text {gas }}$ is the Bunsen absorption coefficient $(\mathrm{L} / \mathrm{L})$ for target gas $\left(\mathrm{H}_{2}\right.$ or $\left.\mathrm{CH}_{4}\right)$ described before. The $S F>1$ and $S F<1$ indicate a super- and undersaturation of the measured dissolved target gas concentration in comparison to the equilibrium with headspace target gases in the gas phase of rumen, respectively.

Frozen rumen content samples were thawed and centrifuged at $12,000 \times g$ for $10 \mathrm{~min}$ at $4^{\circ} \mathrm{C}$, and the supernatants were used for measuring VFA profile by using GC (Agilent 7890A, Agilent Inc., Palo Alto, CA). The estimated net metabolic hydrogen production relative to the amount of total VFA produced $\left(R_{N 2 H}\right)$ was calculated according to the stoichiometric equation developed by Wang et al. (2016b).

\section{DNA Extraction and Quantification of Microbes}

Pooled samples were made by mixing equal volumes of rumen contents collected at 3 sampling time points and freeze-dried. Freeze-dried rumen samples (approximately $0.05 \mathrm{~g}$ ) were homogenized using a bead beater, and microbial DNA was extracted using the QIAamp DNA Stool Mini Kits according to the manufacturer's protocols (Qiagen GmbH, Hilden, Germany). The quality of the DNA extracts was assessed using agarose gel $(0.8 \%)$ electrophoresis, and the quantity of DNA was tested by using a Nano Drop ND-1000 spectrophotometer (NanoDrop Technologies Inc., Wilmington, DE). Total DNA was diluted to $10 \mathrm{ng} / \mu \mathrm{L}$ to quantify methanogens and diluted to $50 \mathrm{ng} / \mu \mathrm{L}$ for Illumina MiSeq sequencing.

The quantitative real-time PCR (qPCR) analysis of methanogens was conducted with ABI $7900 \mathrm{HT}$ 
Fast Real Time PCR system (Applied Biosystems, Foster City, CA), using SYBR Premix Ex Taq (Perfect Real Time, Takara, Shiga, Japan). Forward primer and reverse primer for methanogens were 5'-GGATTAGATACCCSGGTAGT-3' (forward) and 5'-GTTGARTCCAATTAAACCGCA-3' (reverse) (Hook et al., 2009). The standard curve was generated using plasmid DNA containing the insert obtained with the same primers employed. Ten-fold serial dilutions of each standard were made in RNase-free water to qPCR assays. The qPCR reaction system was in total $10 \mu \mathrm{L}$, including $5 \mu \mathrm{L}$ of SYBR Premix Ex Taq, $0.2 \mu \mathrm{L}$ of ROX, $0.2 \mu \mathrm{L}$ of each primer $(10 \mu M), 1 \mu \mathrm{L}$ of the template DNA $(10 \mathrm{ng} / \mu \mathrm{L})$, and $3.4 \mu \mathrm{L}$ of RNase-free water. The program was $95^{\circ} \mathrm{C}$ for $30 \mathrm{~s}$, followed by 40 cycles at $95^{\circ} \mathrm{C}$ for $5 \mathrm{~s}$ and $60^{\circ} \mathrm{C}$ for $30 \mathrm{~s}$ for annealing/ extension. The final melting curve detection with $95^{\circ} \mathrm{C}$ for $15 \mathrm{~s}, 60^{\circ} \mathrm{C}$ for $1 \mathrm{~min}$, and $95^{\circ} \mathrm{C}$ for $15 \mathrm{~s}$. The final 16S rRNA gene copies of targeted microbes per gram of DM of rumen contents were calculated by relating the cycle threshold value to the standard curves. All real-time PCR products were confirmed by agarose gel $(1.8 \%)$ electrophoresis. The results were converted to $\log _{10}$ copies per gram on a DM basis for further statistical analysis.

\section{High-Throughput Sequencing and Analysis}

The extracted DNA samples were pooled for 2 sampling day by equal amount of DNA, and then subjected for PCR amplification of the $16 \mathrm{~S}$ rDNA V4-V5 region of methanogens using universal primers 524F10extF (5'-TGYCAGCCGCCGCGGTAA-3') and Arch958RmodR (5'-YCCGGCGTTGAVTCCAATT-3'). Details for PCR reactions, thermal cycling programing, and purified PCR products were performed according to Ma et al. (2018). Amplicons from each reaction mixture were quantified fluorometrically, normalized, and pooled at equimolar ratios based on the concentration of each amplicon. Amplicons were sequenced with the Illumina MiSeq platform (Illumina, San Diego, CA) at Majorbio Bio-Pharm Technology (Shanghai, China) using protocols recommended by procedures of MiSeq reagent kits v3 (Illumina). Raw reads were submitted to the NCBI Sequence Read Archive (SRA) database under accession number SRP158452. Quality control of the sequence reads were performed using MOTHUR v.1.39.5 (Schloss et al., 2009) and following the protocol described by Kozich et al. (2013). The high-quality reads were clustered into operational taxonomic units at $97 \%$ similarity using Usearch v.7.0 (Edgar, 2013). The taxonomy of each $16 \mathrm{~S}$ rRNA gene sequence was analyzed by RDP Classifier (http://rdp.cme.msu.edu/) against the silva (SSU115)16S rRNA database using confidence threshold of $70 \%$ (Amato et al., 2013). Alpha diversity of methanogen communities was obtained using Mothur v.1.30.1. A principal coordinate analysis was performed at genus level based on Bray-Curtis similarity distances (Bray and Curtis, 1957).

\section{Statistical Analysis}

Statistical analyses were performed using SPSS 21.0 software (SPSS Inc., Chicago, IL). All data were analyzed using a Mixed linear model including treatment as fixed effects, and block as a random effect. When sampling time was included, the model included treatment, interaction between treatment and sampling time as fixed effect, sampling time as repeated measurement, and block as a random effect. Statistical significance was assumed at $P \leq 0.05$ and tendencies at $0.05<P \leq$ 0.10 for all analyses.

\section{RESULTS AND DISCUSSION}

Rumen cannulation can result in various postsurgery complications, such as loose fit of the cannula due to stretching or necrosis of the incision site (Komarek, 1981). This leads to leakage of rumen contents and loss of $\mathrm{CO}_{2}, \mathrm{CH}_{4}$, and $\mathrm{H}_{2}$ from the gas cap of the rumen (Moate et al., 2013). In our study, rumen cannulation decreased headspace $\mathrm{gH}_{2}(P<0.001)$ and $\mathrm{gCH}_{4}(P<$ 0.001 ) concentration in the gas phase of rumen (Table $1)$. We found an interaction between treatment and sampling time $(P=0.005)$ for $\mathrm{gH}_{2}$ concentration. For example, the increase of headspace $\mathrm{gH}_{2}$ concentration between 0 and $2.5 \mathrm{~h}$ postfeeding was less pronounced in cannulated $(2.83$ to $7.71 \mu M)$ compared with intact cows $(9.38$ to $44.57 \mu M)$. Increase of headspace $\mathrm{gH}_{2}$ concentration with sampling time is far less in cannulated animals, which may be due to leakage of $\mathrm{gH}_{2}$ after feeding.

Headspace gases concentration may not be associated with the corresponding dissolved gases, because dissolved gases are always supersaturated in the liquid phase of the rumen (Wang et al., 2016a). In our study, both $\mathrm{dH}_{2}$ and $\mathrm{dCH}_{4}$ had a saturation factor larger than 1 , which indicates supersaturation. Super-saturation of dissolved gases suppresses exchange of gases from the liquid to the gas phase of the rumen. Rumen cannulation increased the concentration of $\mathrm{dCH}_{4}(P<0.001)$ and the saturation factor of $\mathrm{dCH}_{4}(P=0.001$; Table 1$)$. However, rumen cannulation did not alter $(P=0.90)$ $\mathrm{dH}_{2}$ concentration, but increased $(P=0.001)$ saturation factor of $\mathrm{dH}_{2}$. The point of supersaturation is not the same for different gases, and can be affected by many factors, such as viscosity or surface tension of the rumen fluid and rumen motility. Rumen cannulation 
Table 1. Effects of rumen cannulation on gaseous and dissolved gases concentration in the rumen of dairy cows $(n=4)$

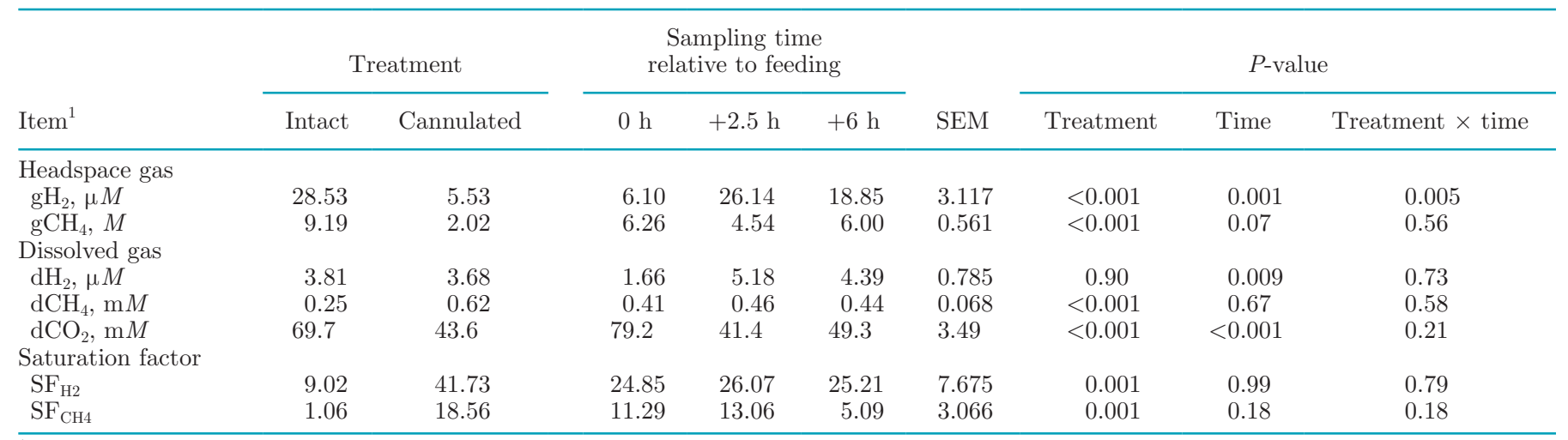

$\overline{{ }^{1} \mathrm{gH}_{2}}=$ gaseous hydrogen; $\mathrm{gCH}_{4}=$ gaseous methane; $\mathrm{dH}_{2}=$ dissolved hydrogen; $\mathrm{dCH}_{4}=$ dissolved methane; dCO ${ }_{2}=$ dissolved carbon dioxide; $\mathrm{SF}_{\mathrm{H} 2}=$ saturation factor of dissolved hydrogen; $\mathrm{SF}_{\mathrm{CH} 4}=$ saturation factor of dissolved methane.

decreases amplitude of the contraction of the rumen (Hirayama and Katoh, 2005), which may help to conserve the dissolved gases in the liquid phase of rumen.

Changes in rumen methanogenesis are commonly associated with shift of rumen fermentation, because $\mathrm{CH}_{4}$ and propionate are electron sinks for reducing equivalents (Janssen, 2010). In our study, rumen cannulation did not $(P>0.10)$ alter molar percentage of major individual VFA, except valerate $(P=0.004)$ (Table 2$)$. This slight change in VFA profile did not $(P>0.10)$ alter estimated metabolic hydrogen production relative to the amount of total VFA produced, and thus was not the main cause of increased $\mathrm{dCH}_{4}$ concentration in this study. Furthermore, rumen cannulation increased $(P<0.001)$ total VFA concentration (Table 2$)$. We speculated that the increased total VFA concentration might be due to the reduction in ruminal passage rate or VFA absorption rate. Hirayama and Katoh (2005) reported that the amplitude of rumen contraction in goats decreased after rumen fistulation, leading to a reduction in ruminal passage rate.

Although cannulation increased supersaturation of $\mathrm{dH}_{2}$ and $\mathrm{dCH}_{4}$, it decreased $\mathrm{dCO}_{2}$ concentration ( $P$ $<0.001$ ) in the liquid phase of rumen (Table 1). The decreased $\mathrm{dCO}_{2}$ may be caused by the leakage of headspace $\mathrm{CO}_{2}$ from the rumen. Rumen cannulation disrupts the strictly anaerobic rumen environment, due to the influx of atmospheric $\mathrm{gO}_{2}$ through the gap between rumen wall and cannula (Moate et al., 2013). Influx of $\mathrm{gO}_{2}$ into the headspace of the rumen has the potential to alter its strictly anaerobic microbial ecosystem. Particularly rumen methanogens have been reported to be sensitive to elevated $\mathrm{gO}_{2}$ concentrations (Moate et al., 2013). Furthermore, $\mathrm{dCO}_{2}$ is an important precursor of methanogenesis (Oppermann et al., 1961; Leahy et al., 2010), and can influence the growth and activity of methanogens (Laporte-Uribe, 2016). However, in this study, rumen cannulation led to an increase in $\mathrm{dCH}_{4}$

Table 2. Effects of rumen cannulation on rumen fermentation in dairy cows $(\mathrm{n}=4)$

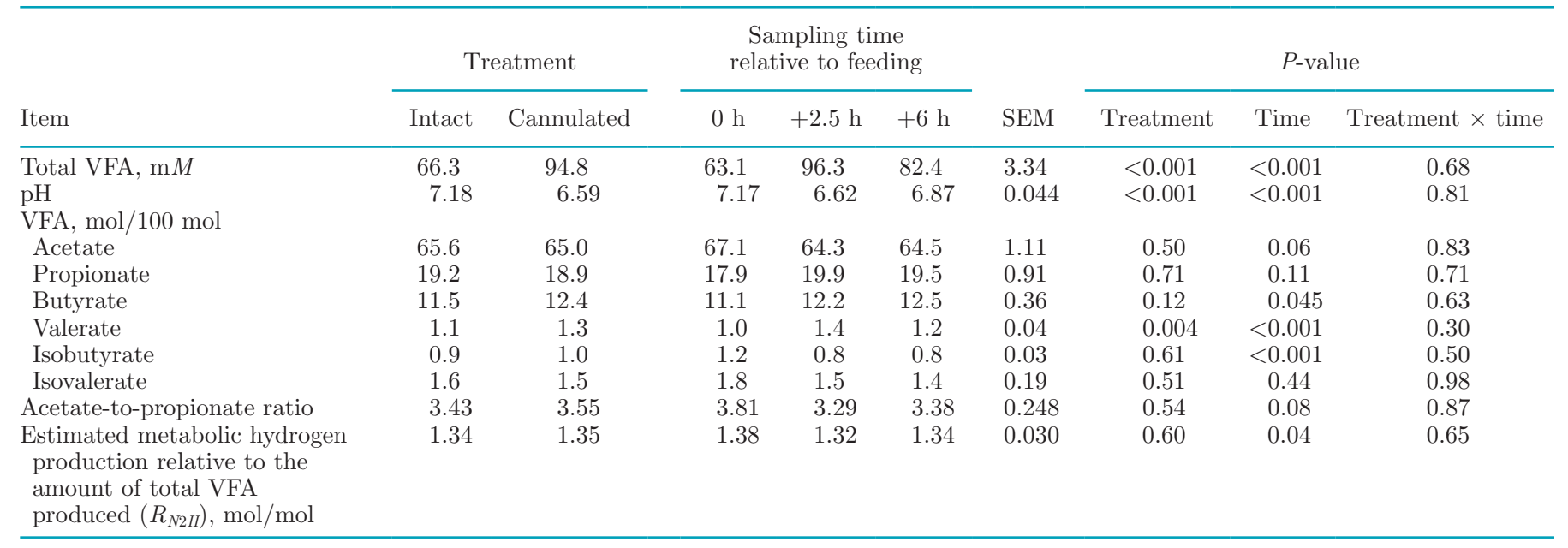




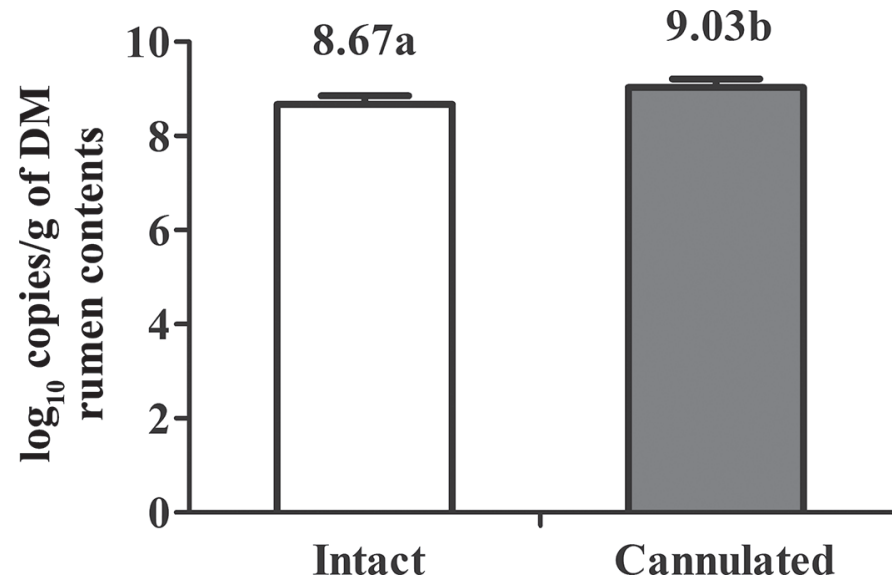

Figure 1. Effect of rumen cannulation on $16 \mathrm{~S}$ rRNA gene copies of methanogens in dairy cows $(\mathrm{n}=4)$. Means with different letters differ $(P \leq 0.05)$. Error bars $=$ SEM.

$(P<0.001)$ and $16 \mathrm{~S}$ rRNA copies specific to methanogens $(P=0.01$; Figure 1$)$ even though $\mathrm{dCO}_{2}$ decreased in response to cannulation. This contradiction can be caused by the increased saturation factor of $\mathrm{dCH}_{4}$ in cannulated cows. Methanogenesis is not only affected by the number of methanogens but as well by their metabolic activity (Kittelmann et al., 2014), which is strongly dependent on the environmental conditions in the rumen (Candyrine et al., 2018; Wang et al., 2018b). Increased methanogen population may not necessarily be correlated with the enhanced methanogenesis ( $\mathrm{Su}$ et al., 2014; Danielsson et al., 2017), because methanogens can grow and may not express genes encoding methanogenesis depending on rumen environment.

The community of methanogens was further analyzed by using high-throughput sequencing. Animal to animal variation accounted for $85 \%$ of the differences in methanogen community structure on a genus level (Figure 2). This large degree of variation among cows might have been caused by differences in lactation status, age, and level of feed intake (Cersosimo et al., 2016; Li et al., 2017). Although treatment only explained $8 \%$ of the variation in methanogen community structure, cannulated cows had a distinctly different methanogen community at the genus level compared with intact cows (Figure 2). Rumen cannulation increased $(P=$ $0.03)$ Simpson index of methanogen community, and decreased $(P=0.01)$ the relative abundance of Methanosphaera (Table 3). Miller and Wolin (1985) reported that the surface of Methanosphaera is smooth without any organized structural pattern, which makes it more sensitive to changes in rumen environment. In our study, Methanosphaera were more sensitive to rumen cannulation, compared with other genus of methanogens.

In summary, rumen cannulation causes loss of headspace gases from the rumen, leading to reductions in headspace $\mathrm{gCH}_{4}$ and $\mathrm{gH}_{2}$, and ruminal $\mathrm{dCO}_{2}$ concentration. However, rumen cannulation increases saturation factor of $\mathrm{dH}_{2}$ and $\mathrm{dCH}_{4}$, which helps to conserve the $\mathrm{dH}_{2}$ and $\mathrm{dCH}_{4}$ in the liquid phase of rumen, so that the ruminal gas leakage does not cause decreases in $\mathrm{dH}_{2}$ and $\mathrm{dCH}_{4}$. Rumen cannulation alters methanogen community structure, with increased methanogen population but reduced abundance of Methanosphaera.

\section{ACKNOWLEDGMENTS}

This work was supported by National Natural Science Foundation of China (grant no. 31561143009 and 31472133), the National Key Research and Development Program of China (grant no. 2016YFD0500504 and 2018YFD0501800), State Key Laboratory of Animal Nutrition (grant no. 2004DA125184F1705), Hunan Province Science and Technology Plan (grant no. 2015WK3043), China Agriculture Research System (grant no. CARS-36), Youth Innovation Promotion

Table 3. Effect of rumen cannulation on $\alpha$ diversity and methanogen community (genus level) based on 16S rRNA gene amplicon sequencing data in dairy cows $(n=4)$

\begin{tabular}{|c|c|c|c|c|}
\hline Item & \multicolumn{2}{|c|}{ Treatment } & SEM & $P$-value \\
\hline \multicolumn{5}{|c|}{ Alpha diversity indices estimated by amplicon sequences } \\
\hline Sobs & 20.00 & 16.00 & 4.183 & 0.52 \\
\hline Chao & 20.71 & 16.81 & 4.193 & 0.54 \\
\hline Ace & 23.35 & 20.70 & 4.026 & 0.66 \\
\hline Shannon & 0.97 & 0.86 & 0.042 & 0.10 \\
\hline Methanobrevibacter & 93.98 & 95.66 & 0.840 & 0.21 \\
\hline Methanosphaera & 2.21 & 0.95 & 0.250 & 0.01 \\
\hline Methanocorpusculum & 0.01 & 0.10 & 0.05 & 0.21 \\
\hline Others 1 & 3.81 & 3.28 & 0.82 & 0.67 \\
\hline
\end{tabular}




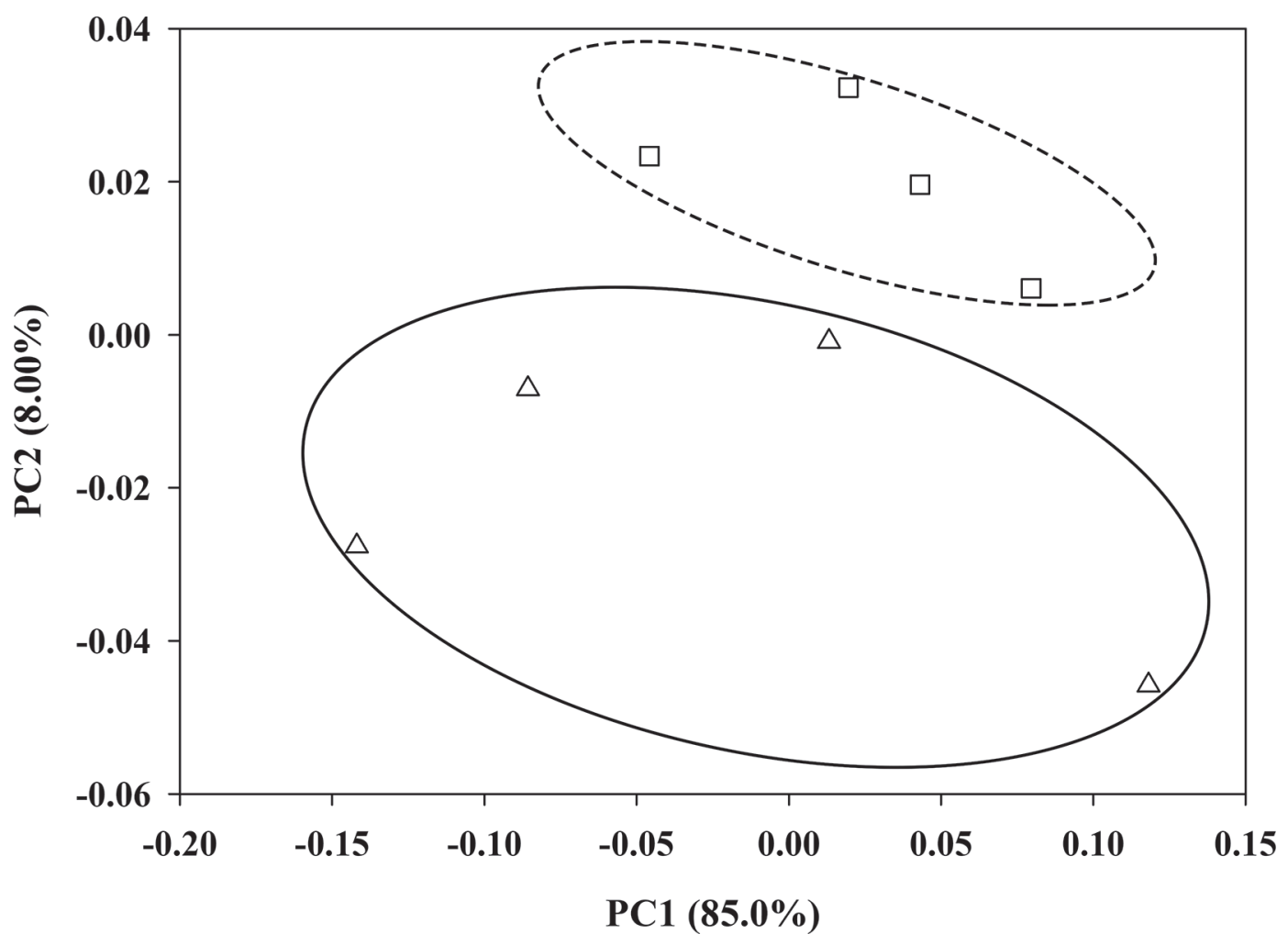

Figure 2. Principal coordinate analysis of rumen methanogen community at genus level based on 16S rRNA gene amplicon sequence data in intact $(\square)$ and cannulated $(\Delta)$ dairy cows $(\mathrm{n}=8)$, with first 2 principal coordinates (PC1 and PC2) explaining the largest amount of variation $(>90 \%)$. The solid and dashed circles indicate that intact and rumen cannulated dairy cows are distinctly separated from each other. Percentage of data variation explained by the analysis is shown in parentheses.

Association of Chinese Academy of Science (CAS, Changsha, Hunan, China; grant no.2016327), and CAS President's International Fellowship (grant no. 2018VBA0031). We also thank Emilio M. Ungerfeld from Instituto de Investigaciones Agropecuarias (INIA) Carillanca (Temuco, Chile) for discussion. The authors declare that they have no conflict of interest.

\section{REFERENCES}

Amato, K. R., C. J. Yeoman, A. Kent, N. Righini, F. Carbonero, A. Estrada, H. R. Gaskins, R. M. Stumpf, S. Yildirim, and M. Torralba. 2013. Habitat degradation impacts black howler monkey ( $\mathrm{Al}$ ouatta pigra) gastrointestinal microbiomes. ISME J. 7:1344-1353. https://doi.org/10.1038/ismej.2013.16.

Bray, J. R., and J. T. Curtis. 1957. An ordination of the upland forest communities of southern Wisconsin. Ecol. Monogr. 27:325-349. https://doi.org/10.2307/1942268.

Candyrine, S. C. L., M. F. Mahadzir, S. Garba, M. F. Jahromi, M. Ebrahimi, Y. M. Goh, A. A. Samsudin, A. Q. Sazili, W. L. Chen, S. Ganesh, R. Ronimus, S. Muetzel, and J. B. Liang. 2018. Effects of naturally-produced lovastatin on feed digestibility, rumen fermentation, microbiota and methane emissions in goats over a 12week treatment period. PLoS One 13:e0199840. https://doi.org/10 .1371/journal.pone.0199840.

Cersosimo, L. M., M. L. Bainbridge, J. Kraft, and A. D. G. Wright. 2016. Influence of periparturient and postpartum diets on rumen methanogen communities in three breeds of primiparous dairy cows. BMC Microbiol. 16:76. https://doi.org/10.1186/s12866-016 $-0694-7$.

Danielsson, R., J. Dicksved, L. Sun, H. Gonda, B. Muller, A. Schnurer, and J. Bertilsson. 2017. Methane production in dairy cows correlates with rumen methanogenic and bacterial community structure. Front. Microbiol. 8:226. https://doi.org/10.3389/fmicb.2017 .00226 .

Edgar, R. C. 2013. UPARSE: Highly accurate OTU sequences from microbial amplicon reads. Nat. Methods 10:996-998. https://doi .org/10.1038/nmeth.2604.

Grovum, W. L. 1989. An improved rumen cannulation technique to minimize leakage. Acta Vet. Scand. Suppl. 86:225-228.

Hirayama, T., and K. Katoh. 2005. Effects of fistula size on rumen internal pressure and passage rate of feed in goats. Small Rumin. Res. 56:277-280. https://doi.org/10.1016/j.smallrumres.2004.06 .004 .

Hook, S. E., K. S. Northwood, A.-D. Wright, and B. W. McBride. 2009. Long-term monensin supplementation does not significantly affect the quantity or diversity of methanogens in the rumen of the lactating dairy cow. Appl. Environ. Microbiol. 75:374-380. https:/ /doi.org/10.1128/AEM.01672-08.

Janssen, P. H. 2010. Influence of hydrogen on rumen methane formation and fermentation balances through microbial growth kinetics and fermentation thermodynamics. Anim. Feed Sci. Technol. 160:1-22. https://doi.org/10.1016/j.anifeedsci.2010.07.002.

Kittelmann, S., C. S. Pinares-Patino, H. Seedorf, M. R. Kirk, S. Ganesh, J. C. McEwan, and P. H. Janssen. 2014. Two different bacterial community types are linked with the low-methane emission trait in sheep. PLoS One 9:e103171. https://doi.org/10.1371/ journal.pone.0103171. 
Komarek, R. J. 1981. Rumen and abomasal cannulation of sheep with specially designed cannulas and a cannula insertion instrument. J. Anim. Sci. 53:790-795. https://doi.org/10.2527/jas1981.533790x.

Kozich, J. J., S. L. Westcott, N. T. Baxter, S. K. Highlander, and P. D. Schloss. 2013. Development of a dual-index sequencing strategy and curation pipeline for analyzing amplicon sequence data on the MiSeq Illumina sequencing platform. Appl. Environ. Microbiol. 79:5112-5120. https://doi.org/10.1128/AEM.01043-13.

Laporte-Uribe, J. A. 2016. The role of dissolved carbon dioxide in both the decline in rumen $\mathrm{pH}$ and nutritional diseases in ruminants. Anim. Feed Sci. Technol. 219:268-279. https://doi.org/10.1016/j .anifeedsci.2016.06.026.

Leahy, S. C., W. J. Kelly, E. Altermann, R. S. Ronimus, C. J. Yeoman, D. M. Pacheco, D. Li, Z. Kong, S. McTavish, and C. Sang. 2010. The genome sequence of the rumen methanogen Methanobrevibacter ruminantium reveals new possibilities for controlling ruminant methane emissions. PLoS One 5:e8926. https://doi.org/ 10.1371/journal.pone.0008926.

Li, X. H., C. Liu, Y. X. Chen, R. G. Shi, Z. H. Cheng, and H. M. Dong. 2017. Effects of mineral salt supplement on enteric methane emissions, ruminal fermentation and methanogen community of lactating cows. Anim. Sci. J. 88:1049-1057. https://doi.org/10 $.1111 /$ asj. 12738 .

Ma, Z., R. Wang, M. Wang, X. Zhang, H. Mao, and Z. Tan. 2018. Variability in fermentation end-products and methanogen communities in different rumen sites of dairy cows. J. Dairy Sci. 101:5153-5158. https://doi.org/10.3168/jds.2017-14096.

McSweeney, C. S. 1989. Cannulation of the rumen in cattle and buffaloes. Aust. Vet. J. 66:266-268. https://doi.org/10.1111/j.1751 -0813.1989.tb13589.x

Mendoza, A., C. Cajarville, and J. L. Repetto. 2016. Digestive response of dairy cows fed diets combining fresh forage with a total mixed ration. J. Dairy Sci. 99:8779-8789. https://doi.org/10.3168/ jds.2016-11023.

Miller, T. L., and M. J. Wolin. 1985. Methanosphaera stadtmaniae gen. nov., sp. nov.: A species that forms methane by reducing methanol with hydrogen. Arch. Microbiol. 141:116-122. https://doi.org/10 $.1007 / \mathrm{bf00423270.}$

Moate, P., T. Clarke, L. Davis, and R. Laby. 1997. Rumen gases and bloat in grazing dairy cows. J. Agric. Sci. 129:459-469. https://doi .org/10.1017/S0021859697004930.

Moate, P., S. Williams, M. Deighton, J. Jacobs, and W. Wales. 2013. Influence of rumen cannulation on feed intake, milk production, enteric methane production and composition of rumen headspace gas. Page 423 in Proc. Greenhouse Gases and Animal Agriculture Conference, Advances in Animal Biosciences.

Mutsvangwa, T., K. L. Davies, J. J. McKinnon, and D. A. Christensen. 2016. Effects of dietary crude protein and rumen-degradable protein concentrations on urea recycling, nitrogen balance, omasal nutrient flow, and milk production in dairy cows. J. Dairy Sci. 99:6298-6310. https://doi.org/10.3168/jds.2016-10917.
Oppermann, R. A., W. Nelson, and R. Brown. 1961. In vivo studies of methanogenesis in the bovine rumen: Dissimilation of acetate. J. Gen. Microbiol. 25:103-111.

Rafee, M. A., S. Sinha, and A. Saxena. 2015. Fistulation and cannulation of the rumen in buffaloes: Comparison of two methods. Int. J. Vet. Health. Sci. Res. 3:64-65. https://doi.org/10.19070/2332 $-2748-1500016$.

Schloss, P. D., S. L. Westcott, T. Ryabin, J. R. Hall, M. Hartmann, E. B. Hollister, R. A. Lesniewski, B. B. Oakley, D. H. Parks, and C. J. Robinson. 2009. Introducing mothur: Open-source, platformindependent, community-supported software for describing and comparing microbial communities. Appl. Environ. Microbiol. 75:7537-7541. https://doi.org/10.1128/AEM.01541-09.

Su, X. L., Q. Tian, J. Zhang, X. Z. Yuan, X. S. Shi, R. B. Guo, and Y. L. Qiu. 2014. Acetobacteroides hydrogenigenes gen. nov., sp nov. an anaerobic hydrogen-producing bacterium in the family Rikenellaceae isolated from a reed swamp. Int. J. Syst. Evol. Microbiol. 64:2986-2991. https://doi.org/10.1099/ijs.0.063917-0.

Wang, L., D. Wu, T. Yan, and L. Wang. 2018a. The impact of rumen cannulation on the microbial community of goat rumens as measured using 16S rRNA high-throughput sequencing. J. Anim. Physiol. Anim. Nutr. (Berl.) 102:175-183. https://doi.org/10 $.1111 /$ jpn. 12676 .

Wang, M., X. Z. Sun, P. H. Janssen, S. X. Tang, and Z. L. Tan. 2014. Responses of methane production and fermentation pathways to the increased dissolved hydrogen concentration generated by eight substrates in in vitro ruminal cultures. Anim. Feed Sci. Technol. 194:1-11. https://doi.org/10.1016/j.anifeedsci.2014.04.012.

Wang, M., E. M. Ungerfeld, R. Wang, C. S. Zhou, Z. Z. Basang, S. M. Ao, and Z. L. Tan. 2016a. Supersaturation of dissolved hydrogen and methane in rumen of Tibetan sheep. Front. Microbiol. 7:850. https://doi.org/10.3389/fmicb.2016.00850.

Wang, M., R. Wang, P. H. Janssen, X. M. Zhang, X. Z. Sun, D. Pacheco, and Z. L. Tan. 2016b. Sampling procedure for the measurement of dissolved hydrogen and volatile fatty acids in the rumen of dairy cows. J. Anim. Sci. 94:1159-1169. https://doi.org/10.2527/ jas.2015-9658.

Wang, M., R. Wang, X. Zhang, E. M. Ungerfeld, D. Long, H. Mao, J. Jiao, K. A. Beauchemin, and Z. Tan. 2017. Molecular hydrogen generated by elemental magnesium supplementation alters rumen fermentation and microbiota in goats. Br. J. Nutr. 118:401-410. https://doi.org/10.1017/S0007114517002161.

Wang, R., M. Wang, E. M. Ungerfeld, X. M. Zhang, D. L. Long, H. X. Mao, J. P. Deng, A. Bannink, and Z. L. Tan. 2018b. Nitrate improves ammonia incorporation into rumen microbial protein in lactating dairy cows fed a low-protein diet. J. Dairy Sci. 101:97899799. https://doi.org/10.3168/jds.2018-14904.

Wiesenburg, D. A., and N. L. Guinasso. 1979. Equilibrium solubilities of methane, carbon-monoxide, and hydrogen in water and seawater. J. Chem. Eng. Data 24:356-360. https://doi.org/10.1021/ je60083a006. 